\title{
Tailoring the immobilization and release of chlorhexidine using dopamine chemistry to fight infections associated to orthopedic devices
}

\author{
Diana Alves *, Patrick Borges, Tânia Grainha, Célia F. Rodrigues, Maria Olívia Pereira \\ CEB - Centre of Biological Engineering, LIBRO - Laboratório de Investigação em Biofilmes Rosário Oliveira, University of Minho, Campus de Gualtar, $4710-057$ Braga, \\ Portugal
}

\section{A R T I C L E I N F O}

\section{Keywords:}

Implant-related infections

Antimicrobial-releasing coating

Chlorhexidine

Dopamine chemistry

\begin{abstract}
A B S T R A C T
A crucial factor in the pathogenesis of orthopedics associated infections is that bacteria do not only colonize the implant surface but also the surrounding tissues. This study aimed to engineer an antimicrobial release coating for stainless steel (SS) surfaces, to impart them with the ability to prevent Staphylococci colonization. Chlorhexidine (CHX) was immobilized using two polydopamine (pDA)-based approaches: a one-pot synthesis, where CHX is dissolved together with dopamine before its polymerization; and a two-step methodology, comprising the deposition of a pDA layer to which CHX is immobilized. To modulate CHX release, an additional layer of pDA was also added for both strategies.

Immobilization of CHX using a one-step approach yielded surfaces with a more homogenous coating and less roughness than the other strategies. The amount of released $\mathrm{CHX}$ was lower for the one-step approach, as opposed to the two-step approach yielding the higher release, which could be decreased by applying an outward layer of pDA. Both one and two-step approaches provided the surfaces with the ability to prevent bacterial colonization of the surface itself and kill most of bacteria in the bulk phase up to 10 days. This long-term antimicrobial performance alluded a stable and enduring immobilization of CHX. In terms of biocompatibility, the amount of CHX released from the one-step approach did not compromise the growth of mammalian cells, contrary to the two-step strategy. Additionally, the few bacteria that managed to adhere to surfaces modified with one-step approach did not show evidence of resistance towards CHX.

Overall data underline that one-step immobilization of CHX holds great potential to be further applied in the fight against orthopedic devices associated infections.
\end{abstract}

\section{Introduction}

Orthopedic implants have been widely used to restore the function of load-bearing joints, reducing the pain and improving the life quality of millions of people every year [1]. Knee and hip replacements are the most common procedures in this field and it has been estimated that by the end of 2030, the number of total knee arthroplasties and hip replacements will grow $673 \%$ and $174 \%$, respectively, just in the United States [2]. Inserting an implant in the body is always associated with the risk of microbial infection. Indeed, infection is one of the major complications in orthopedics, being the cause of failure of total hip and knee arthroplasties in 1 to $5 \%$ of the almost half a million annually performed worldwide $[3,4]$.

Upon implantation, the fate of a biomaterial has been described as a race between its integration into the surrounding tissue and bacterial adhesion to its surface [5]. When successful, the race is won by tissue cells and the surface will be less vulnerable to bacterial colonization. Conversely, if the race is won by bacteria, the implant surface will become rapidly covered by a biofilm, a structured community of adhering cells encased in a self-produced polymeric matrix [5,6]. Once established, biofilm-associated infections are extremely difficult to treat because cells within biofilms are less susceptible to both antimicrobial treatment and the host immune system. Furthermore, the emerging microbial resistance towards the widely prescribed antibiotics compromises their successful use for treatment purposes [7]. Staphylococcus aureus and coagulase-negative staphylococci such as $S$. epidermidis are the two most frequently implicated organisms in prosthetic joint infections, with incidence rates of $24-43 \%$ and $12-26 \%$, respectively [8].

The more desirable option to fight biomaterial-associated infections (BAI) relies, therefore, on the development of materials able to resist

\footnotetext{
* Corresponding author.

E-mail address: dianalves@ceb.uminho.pt (D. Alves).
} 
bacterial colonization in the first place, while enhancing tissue integration [9]. Several surface modifications have been proposed to address these infections, including impregnation with compounds such as silver or antibiotics $[10,11]$. Orthopedic devices currently in the market, and approved for human clinical use, are based on antibiotic eluting [12,13]. Such strategies, however, are not able to fully address the increasing infection rates while antibiotics overuse paves a strong selective pressure on bacteria, resulting in the emergence and spread of resistant bacteria [14]. Chlorhexidine (CHX), an antiseptic biguanide compound, has been described as a promising compound to be immobilized on the surface of implants and, therefore, replace the need to use antibiotics in the treatment of BAI [15]. Its appealing features include mostly its efficiency against a broad spectrum of relevant pathogens, including Gram-positive and Gram-negative bacteria and yeasts. In addition, it has already been accounted for a number of applications, including oral and skin antiseptics [16,17], as well as in intracorporeally used medical devices such as catheters and meshes [18,19]. Another promising feature involves CHX substantivity, since this agent not only has an immediate antimicrobial effect but it also persists for periods of time longer than the application period [20,21]. As a positively charged molecule, it has been postulated that CHX's main mode of action is mainly based on interactions with the anionic phosphate residue of the lipid molecules in the cell membrane, bypassing the cell wall exclusion mechanism, in which it causes intracellular components leakage and cytoplasm content precipitation [22,23].

Amongst the great number of coating strategies reported to impart the surfaces of biomaterials with the ability to resist microbial colonization [24], mussel-inspired polydopamine (pDA) has aroused researcher's attention mainly due to its simple processing conditions, material independency, strong reactivity for secondary functionalization and positive interactions with mammalian cells [25]. This coating strategy, based on a mussel adhesive protein, was first described in 2007 by Messersmith and co-workers and it comprises the immersion of substrates in an alkaline solution of dopamine, which selfpolymerization results in the deposition of an adhesive film with nanometer thickness [26]. It has been successfully applied for the immobilization of antifungals, antimicrobial peptides and enzymes to render the surfaces of biomaterials with anti-infective properties [27-29].

The main purpose of the present study was to explore this musselinspired coating strategy to tailor the immobilization and subsequent release of CHX from stainless steel (SS) surfaces, in order to both prevent $S$. aureus and $S$. epidermidis attachment to these surfaces and impair bacterial growth in their surroundings.

\section{Materials and methods}

\subsection{Bacterial strains and growth conditions}

The reference strain ATCC 25923 Staphylococcus aureus (purchased by the American Type Culture Collection) and the reference strain CECT 231 Staphylococcus epidermidis (purchased by the Spanish Type Culture Collection) were used in this study. Bacteria were first streaked on a tryptic soy agar (TSA, Liofilchem) plate, from a frozen stock solution and grown for $24 \mathrm{~h}$ at $37^{\circ} \mathrm{C}$. A few colonies were then collected from the TSA plates and grown overnight in batches of tryptic soy broth (TSB, Liofilchem) at $37^{\circ} \mathrm{C}$ under agitation (OS-20, $120 \mathrm{rpm}$ ). Cells were harvested by centrifugation $(9000 \mathrm{~g}, 5 \mathrm{~min}$ ) and washed in sterile saline solution $(0.9 \% \mathrm{NaCl})$. The concentration of cellular suspensions was adjusted by measuring the absorbance at $620 \mathrm{~nm}$ (EZ Read 800 Plus, Biochrom) and using an established standard curve for each species.

\subsection{Determination of minimal inhibitory and bactericidal concentrations}

The minimal inhibitory (MIC) and bactericidal (MBC) concentrations of CHX (Sigma, Portugal) were determined by the microdilution method, in accordance to Clinical and Laboratory Standards Institute (formerly NCCLS) [30]. Briefly, the wells of sterile 96-well roundbottom microtiter plates (polystyrene, Orange, USA) were filled with $100 \mu \mathrm{L}$ of TSB with increasing concentrations of CHX, to which were added $100 \mu \mathrm{L}$ of each bacterium inoculums (adjusted to a final concentration of $5.0 \times 10^{5} \mathrm{CFU} \mathrm{mL}{ }^{-1}$ ). The final concentration of CHX tested was in the range of $0.19-50 \mu \mathrm{g} \mathrm{mL}^{-1}$. The plates were afterwards incubated at $37{ }^{\circ} \mathrm{C}$ for $24 \mathrm{~h}$ in an orbital shaker (OS-20, $120 \mathrm{rpm}$ ). In this assay, two controls were used: culture media without bacteria, as a negative control, and bacterial suspension growth without antimicrobials, as a positive control. Moreover, culture media with increasing concentrations of antimicrobials without bacteria were also performed in order to avoid misleading results. The MIC was obtained by measuring the absorbance at $620 \mathrm{~nm}\left(\mathrm{~A}_{620 \mathrm{~nm}}\right)$, in which clear wells $\left(\mathrm{A}_{620 \mathrm{~nm}}=\right.$ $A_{620 n m}$ of negative control) were evidence of bacterial growth inhibition. MBC determination was performed by adding a droplet of $10 \mu \mathrm{L}$ from each well with no visible growth on a TSA plate. The lowest concentration that yielded no colony growth after $24 \mathrm{~h}$ at $37^{\circ} \mathrm{C}$ was identified as the MBC.

\subsection{Stainless steel preparation and further functionalization}

Stainless steel 316 (Ramada Aços, Portugal) was cut into $1 \mathrm{~cm} \times 1 \mathrm{~cm}$ squares. Prior to surface modification, an ultrasonic cleaning pretreatment was performed to remove all impurities and traces of grease. For that, samples were sonicated in distilled water, acetone and ethanol for $10 \mathrm{~min}$ in each solution, being afterwards sterilized by autoclaving at $121{ }^{\circ} \mathrm{C}$ for $15 \mathrm{~min}$. SS modification and functionalization were performed using a mussel-inspired coating strategy as illustrated in Fig. 1. For CHX immobilization using 1-step approach (Fig. 1A), dopamine (Sigma, $2 \mathrm{mg} \mathrm{mL}^{-1}$ ) and CHX $\left(2 \mathrm{mg} \mathrm{mL}^{-1}\right.$ ) were dissolved together in $10 \mathrm{mM}$ bicine buffer (Sigma, $\mathrm{pH} \mathrm{8.5)}$ and the SS coupons were immediately placed in this solution. After an overnight incubation at room temperature and $70 \mathrm{rpm}$, the coupons were rinsed with ultrapure water and air-dried before further utilization. In the 2-step approach (Fig. 1B), SS coupons were first immersed in a freshly prepared solution of dopamine ( $2 \mathrm{mg} \mathrm{mL}^{-1}$ in bicine buffer, $\mathrm{pH} 8.5$ ) for $18 \mathrm{~h}$, at room temperature and $70 \mathrm{rpm}$. After dopamine polymerization, the coupons were rinsed with ultrapure water and, for further functionalization with CHX, pDA-coated coupons were immersed in a CHX solution $\left(2 \mathrm{mg} \mathrm{mL}^{-1}\right.$ in bicine buffer, $\mathrm{pH}$ 8.5), and incubated overnight at room temperature under agitation $(70 \mathrm{rpm})$. The CHX concentration in the prepared solution was confirmed by measuring its absorbance at $255 \mathrm{~nm}$ (Fig. S1 of supporting information). Attempting to modulate CHX release, for both strategies, an additional layer of pDA was added (Fig. 1C) by immersing the modified coupons on a freshly prepared solution of dopamine (2 $\mathrm{mg}$ $\mathrm{mL}^{-1}$ in bicine buffer, $\mathrm{pH} 8.5$ ) for $18 \mathrm{~h}$, at room temperature under agitation $(70 \mathrm{rpm})$. Finally, to prepare a contact-killing approach with no antimicrobial release, for comparison purposes, a commercially available solution containing chlorhexidine gluconate and PEG (Parodontax ${ }^{\circledR}$, called PTX) was immobilized onto SS surfaces, following the two-step pDA-based approach.

\subsection{Surfaces characterization}

Morphological analyses were performed in an ultra-high resolution Field Emission Gun Scanning Electron Microscopy (FEG-SEM, NOVA 200 Nano SEM, FEI Company). Prior to its observation, samples were covered with a very thin film of $\mathrm{Au}-\mathrm{Pd}(80-20 \mathrm{wt} \%)$. Topographic images were obtained with a secondary electron detector using the following parameters: an acceleration voltage of $10 \mathrm{kV}, 6.7 \mathrm{~mm}$ stage distance, and $1000 \times$ and $10,000 \times$ magnification. Chemical analyses were performed with the Energy Dispersive Spectroscopy (EDS) technique, using an EDAX $\mathrm{Si}(\mathrm{Li})$ detector with an acceleration voltage of 4 $\mathrm{kV}$. Fourier transform infrared (FTIR) spectra of the surfaces were recorded with a Bruker Alpha II spectrometer in Attenuated Total 


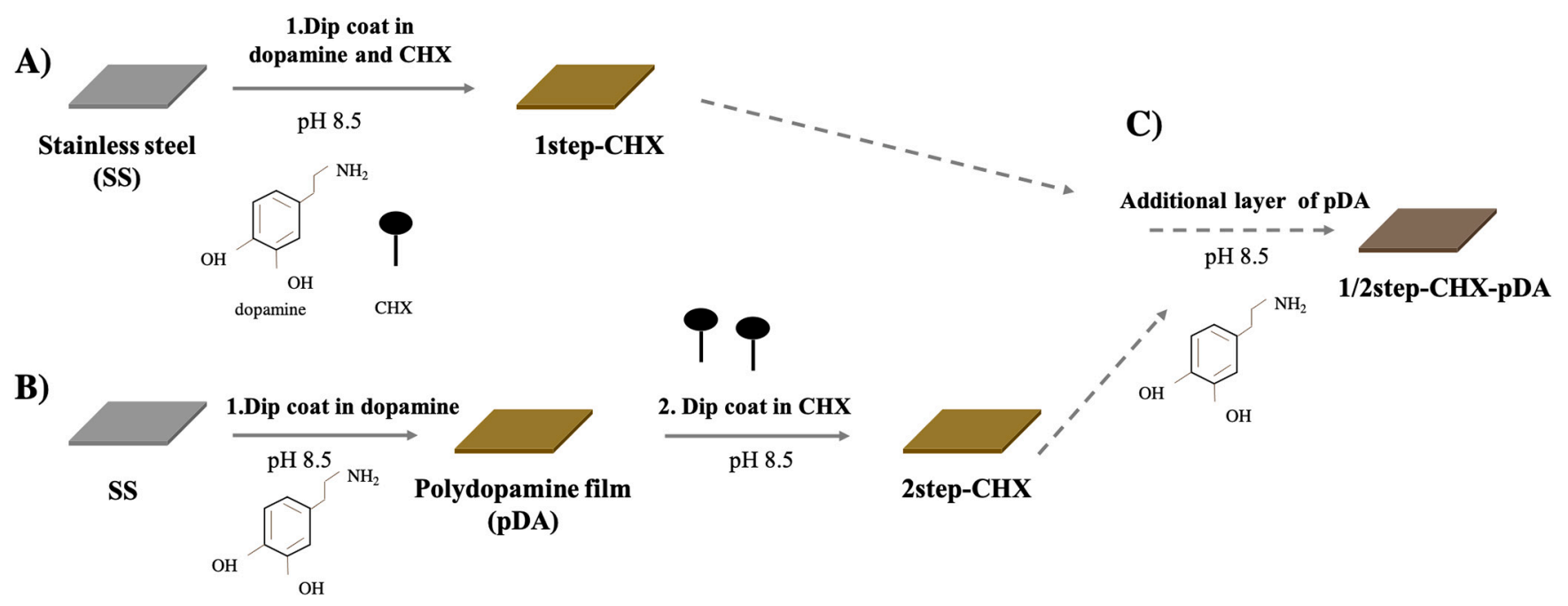

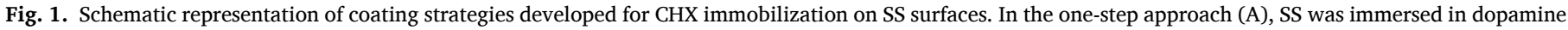

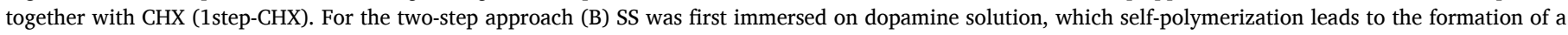

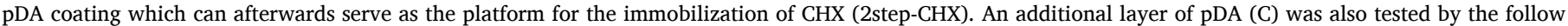
immersion on dopamine solution (1step-CHX-pDA and 2step-CHX-pDA).

Reflectance mode (ATR) with a platinum accessory in the wavenumber range: $4000-500 \mathrm{~cm}^{-1}$, using 64 scans at a resolution of $4 \mathrm{~cm}^{-1}$. Surface morphology and roughness were further analyzed with atomic force microscopy (AFM). AFM measurements were performed at room temperature using a Multimode with a Nanoscope III from Digital Instruments (USA) operating in tapping mode. Scan rates were set at 1.0 $\mathrm{Hz}$ and the scanning area per sample was fixed at $5 \mu \mathrm{m} \times 5 \mu \mathrm{m}$. Surface morphology and roughness analysis were conducted using Gwyddion software. Surface wettability was investigated by measuring SS static water contact angle after each deposition step, by a sessile drop method using an automated contact angle measurement apparatus (OCA 15 Plus, Dataphysics, Germany) that allows image acquisition and data analysis. Contact angles were measured using $3 \mu \mathrm{L}$ drops of water.

\subsection{CHX release profile}

To determine CHX release profile, modified coupons were placed in 6-well microtiter plates (Orange Scientific, USA) to which $4 \mathrm{~mL}$ of PBS (phosphate buffered saline, $\mathrm{pH}$ 7.4) were added, being after constantly agitated at $120 \mathrm{rpm}$ and $37^{\circ} \mathrm{C}$. The PBS was all collected and refreshed by adding more $4 \mathrm{~mL}$ of PBS, at different time points (every hour in the first $6 \mathrm{~h}$ and every $24 \mathrm{~h}$ up to $72 \mathrm{~h}$ ). The amount of released CHX was then determined by ultraviolet-visible spectroscopy (UV-Vis), measuring the absorbance at $255 \mathrm{~nm}$. The absorbance values were then converted to concentration values using a calibration curve previously established.

\subsection{Antimicrobial and leaching properties of modified surfaces}

Antimicrobial properties of prepared surfaces were evaluated as previously reported, with some modifications [27]. Briefly, $20 \mu \mathrm{L}$ of a bacterial suspension adjusted to approximately $10^{6} \mathrm{CFU} \mathrm{mL}{ }^{-1}$ were added on top of each surface and incubated under static conditions at $37^{\circ} \mathrm{C}$. When the drop was dried, coupons were placed on a TSA plate, with the face exposed to bacterial suspension in contact with the agar, and they were incubated at $37^{\circ} \mathrm{C}$ for $24 \mathrm{~h}$. Bacterial growth was then evaluated for the tested surfaces and tabulated as "+" for growth and "-." for no visible growth. To determine the possible leaching of CHX from the modified surfaces, a qualitative method previously reported was used [27]. Surfaces were placed on top of TSA plates previously streaked with a bacterial suspension adjusted to a concentration of approximately $10^{8} \mathrm{CFU} \mathrm{mL}{ }^{-1}$. Plates were then incubated for $72 \mathrm{~h}$ at $37^{\circ} \mathrm{C}$ and the presence or absence of an inhibition zone was observed. The inhibition zone was an indication of CHX release from the surfaces. Three independent assays with three replicates for each condition were performed.

\subsection{Antimicrobial performance of modified surfaces}

Antimicrobial activity of the generated surfaces against bacterial adhesion and subsequent biofilm formation was evaluated by preparing a bacterial suspension with $10^{6} \mathrm{CFU} \mathrm{\textrm {mL } ^ { - 1 }}$ in TSB from overnight cultures of both species. SS coupons were then placed into the wells of a 24well microtiter plate (Orange Scientific, USA) and covered with $1 \mathrm{~mL}$ of each bacterial suspension. The samples were kept at $37^{\circ} \mathrm{C}$ and $120 \mathrm{rpm}$ for $24 \mathrm{~h}$ and 10 days. For the 10 days experiments, $50 \%$ of bacterial suspension was removed and filled with fresh TSB, every $24 \mathrm{~h}$. The supernatants were recovered, and the coupons were washed twice with saline solution and transferred to new wells filled with $1 \mathrm{~mL}$ of saline solution. Adhered cells were removed from the SS coupons by ultrasonic bath in a Sonicor SC-52 (Sonicor Instruments) operating at $50 \mathrm{kHz}$, during $6 \mathrm{~min}$ (parameters previously optimized). The resulting bacterial suspensions were afterwards collected, gently vortexed to disrupt possible cell aggregates, serially 10 -fold diluted, and plated into TSA plates that were incubated overnight at $37^{\circ} \mathrm{C}$ in an aerobic incubator prior enumeration.

\subsection{Assessment of antimicrobial resistance development by planktonic cultures exposed to $\mathrm{CHX}$}

The potential resistance development was first evaluated for planktonic cells with $\mathrm{CHX}$ in solution, adapting a procedure previously described by Cooper et al. [31]. Briefly, $20 \mu \mathrm{L}$ of an overnight culture of $S$. aureus was inoculated in $10 \mathrm{~mL}$ of TSB medium containing a subinhibitory concentration of $\mathrm{CHX}(0.195 \mathrm{mg} / \mathrm{L})$. The flask was then incubated at $37{ }^{\circ} \mathrm{C}$ and $120 \mathrm{rpm}$ for $24 \mathrm{~h}$. For 10 successive days, similar and freshly prepared flasks were inoculated with $20 \mu \mathrm{L}$ of the preceding days' culture. The MIC and MBC of CHX was determined, as aforementioned, on days 0 and 10. Three independent assays were performed.

\subsection{Evaluation of modified surfaces potential to induce bacterial resistance}

To evaluate the potential development of resistance of cells adhered 
towards the immobilized CHX on the SS surfaces, a previously reported procedure [28] was adapted, in which cells adhered to the surfaces with and without modification were collected after 10 days of exposure to these surfaces. Briefly, $1 \mathrm{~mL}$ of a bacterial suspension with $10^{7} \mathrm{CFU}$ $\mathrm{mL}^{-1}$ prepared in TSB was added to a 24-well microtiter plate in which SS, pDA, and pDA further functionalized with CHX using both one and two-step approaches (2step-CHX and 1step-CHX) and Parodontax (PTX) were individually placed. The plate was incubated for 10 days at $37{ }^{\circ} \mathrm{C}$ and $120 \mathrm{rpm}$, with TSB replacement every $24 \mathrm{~h}$. After 10 days, the coupons were subsequently washed twice with saline solution to remove free-floating bacteria, and transferred to new wells filled with $1 \mathrm{~mL}$ of TSB. Adhered cells were removed by ultrasonic bath as aforementioned, being the number of viable cells determined by CFU counts. The recovered cells were adjusted to the same concentration and used for MIC and MBC determination.

\subsection{Cytotoxicity determination}

Cytotoxicity was evaluated on fibroblast 3T3 (CCL-163) cells obtained from ATCC, according to the ISO 10993-5:2006 [32]. Cells were grown in Dulbecco modified eagle medium (DMEM, Gibco) supplemented with $10 \%$ of fetal bovine serum (FBS, Gibco) and $1 \%$ antibiotics (ZellShield ${ }^{\mathrm{TM}}$, Biochrom) at $37{ }^{\circ} \mathrm{C}$ and $5 \% \mathrm{CO}_{2}$. Once achieved the confluence, cells were detached using trypsin and $100 \mu \mathrm{L}$ of cell suspension, adjusted to $1 \times 10^{5}$ cells $\mathrm{mL}^{-1}$, were transferred to each well of a 96-well plate. In parallel, unmodified and modified surfaces were inserted in 24-well plates and $1 \mathrm{~mL}$ of DMEM was added to each well. Both plates with cells and surfaces were incubated for $24 \mathrm{~h}$ at $37^{\circ} \mathrm{C}$ and $5 \% \mathrm{CO}_{2}$. After this period, cells supernatant was removed and $100 \mu \mathrm{L}$ of the medium, which was in contact with the surfaces, were added. Fresh DMEM was also added as a positive control. Plate was then incubated for additional $24 \mathrm{~h}$ at $37{ }^{\circ} \mathrm{C}, 5 \% \mathrm{CO}_{2}$. In the dark, $20 \mu \mathrm{L}$ of MTS (3-(4,5dimethylthiazol-2-yl)-5-(3-carboxymethoxyphenyl)-2-(4-sulfophenyl)$2 \mathrm{H}$-tetrazolium) inner salt (Promega) were added to each well and the plate was further incubated for $1 \mathrm{~h}$ at $37{ }^{\circ} \mathrm{C}, 5 \% \mathrm{CO}_{2}$. The absorbance of the resulting solution was measured at $490 \mathrm{~nm}$. The percentage of cells viability was calculated by the ratio between the cell growth in the presence of coating and the control growth (cells growth in DMEM). Three independent experiments in triplicate were performed.

\subsection{Statistical analysis}

Statistical analysis was performed by Kolmogorov-Smirnov normality test using Graph Pad Prism 7.0. After this analysis, parametric tests (one-way ANOVA followed by Tukey's test) or nonparametric (Kruskal-Wallis test) were used, depending on whether the samples were from normally distributed populations or not, respectively. In all the analysis performed, the confidence interval used was $95 \%$.

\section{Results}

\subsection{Stainless steel functionalization with $\mathrm{CHX}$}

To impart SS surfaces with the ability to resist bacterial colonization, several pDA-based strategies were explored for the immobilization of CHX (Fig. 1). For the one-step pDA-based coating strategy (Fig. 1A), SS coupons were dipped in a mixture of dopamine and CHX. In the two-step approach (Fig. 1B), substrata were first dipped in a solution of dopamine, with its self-polymerization resulting in the deposition of a pDA coating. The quinone functional groups of pDA will allow the covalent grafting of nucleophilic CHX via Michael addition and/or Schiff base reactions [33]. Considering that $\mathrm{CHX}$ has no primary but secondary amines, its reactivity should be lower [34] than other compounds previously immobilized such as enzymes and peptides with primary amines or thiol groups [33]. However, secondary amines should react with carbonyl groups on polydopamine layer to form enamines [35]. On the other hand, the very nature of the functionalization process, which involves surfaces immersion on a solution of $\mathrm{CHX}$, led us to assume that some physical adsorption may occur. Aiming to control the CHX release, a third approach - comprising the deposition of an additional layer of pDA to both strategies (Fig. 1C) - was followed.

The generated coating strategies performance was first evaluated considering their ability to kill bacteria and CHX release from the surfaces (Table 1).

Results showed that both one-step and two-step pDA-based approaches were successful in the immobilization of CHX on SS surfaces, as evidenced by their antimicrobial activity against $S$. epidermidis and $S$. aureus. For both strategies, it was also observed an inhibition zone which indicates $\mathrm{CHX}$ release from the surfaces. Further modification of one-step pDA-based strategy with another layer of pDA masked the antimicrobial activity of CHX, as evidenced by the absence of antimicrobial activity and inhibition zones. Based on these features, this approach was, therefore, no further considered for the following analysis. After adding an additional layer of pDA to the two-step approach, immobilized CHX retained its antimicrobial activity and the ability to release from the surfaces. However, a smaller inhibition zone was observed, as compared to the simple two-step approach, which suggests a different release profile (Fig. S2).

In addition to these antimicrobial-releasing surfaces, a contactkilling design with no antimicrobial release was prepared by the immobilization of a commercially available solution containing chlorhexidine gluconate and PEG (Parodontax ${ }^{\circledR}$ ) following the two-step pDAbased approach (PTX). Results showed that this strategy imparted SS surfaces with contact-killing activity, while no CHX release was observed. Therefore, no other pDA-based strategies were explored for PTX immobilization.

\subsection{Surface characterization}

\subsubsection{Chemical composition}

Chemical analyses of the surfaces were performed using EDS to confirm each modification step (Table 2). Results showed that bare SS is an alloy composed mostly by Iron ( $\mathrm{Fe}$ ) in combination with Nickel (Ni), Carbon (C) and Oxygen (O). It is also composed by other elements but in vestigial amounts, therefore, they were not detected. Polydopamine deposition could be confirmed by the decrease of $\mathrm{Fe}$ and $\mathrm{Ni}$ amounts accompanied by the increase on $\mathrm{C}$ and $\mathrm{N}$ composition. The presence of $\mathrm{Fe}$ and $\mathrm{Ni}$ detected on all the coating strategies may be attributed to the sampling depth achieve by the EDS, which is higher than $50 \mathrm{~nm}$ (maximal thickness of pDA-based coatings) [26,36]. It is expected, therefore, that SS chemical signature will be always detected. CHX immobilization was suggested for both one-step and two-step approaches taking into account the continuous decrease on $\mathrm{Fe}$ and $\mathrm{Ni}$ composition and the increase on $\mathrm{C}$ content. A greater reduction on $\mathrm{Fe}$

\section{Table 1}

Antimicrobial activity and qualitative release of CHX from SS surfaces functionalized with CHX/PTX, using different pDA-based coating strategies. Visible growth was used as an indication of antimicrobial activity being tabulated as "+" for bacterial growth and "-" for no growth. Release of CHX/PTX was evaluated by the presence (P) or absence (A) of an inhibition zone.

\begin{tabular}{|c|c|c|c|c|}
\hline \multirow{2}{*}{$\begin{array}{l}\text { Coating } \\
\text { strategies }\end{array}$} & \multicolumn{2}{|c|}{ S. epidermidis } & \multicolumn{2}{|l|}{ S. aureus } \\
\hline & $\begin{array}{l}\text { Bacterial } \\
\text { growth }\end{array}$ & $\begin{array}{l}\text { Inhibition } \\
\text { zone }\end{array}$ & $\begin{array}{l}\text { Bacterial } \\
\text { growth }\end{array}$ & $\begin{array}{l}\text { Inhibition } \\
\text { zone }\end{array}$ \\
\hline 1step-CHX & - & $P$ & - & $\mathrm{P}$ \\
\hline 2step-CHX & - & $\mathrm{P}$ & - & $\mathrm{P}$ \\
\hline $\begin{array}{l}\text { 1step-CHX- } \\
\text { pDA }\end{array}$ & + & A & + & A \\
\hline $\begin{array}{l}\text { 2step-CHX- } \\
\text { pDA }\end{array}$ & - & $\mathrm{P}$ & - & $\mathrm{P}$ \\
\hline PTX & - & A & - & A \\
\hline
\end{tabular}


Table 2

EDS quantification of atomic compositions of SS surfaces before and after different pDA-based coating strategies for the immobilization of CHX/PTX.

\begin{tabular}{lrrrrr}
\hline Surfaces & $\mathrm{C}(\%)$ & $\mathrm{O}(\%)$ & $\mathrm{N}(\%)$ & $\mathrm{Fe}(\%)$ & $\mathrm{Ni}(\%)$ \\
\hline SS & 18.34 & 15.66 & 0.00 & 52.71 & 13.29 \\
pDA & 32.36 & 14.41 & 8.33 & 36.27 & 8.63 \\
1step-CHX & 50.27 & 15.72 & 7.00 & 21.99 & 5.02 \\
2step-CHX & 46.39 & 14.02 & 9.54 & 24.71 & 5.34 \\
2step-CHX-pDA & 56.85 & 13.79 & 9.47 & 16.23 & 3.67 \\
PTX & 37.90 & 12.32 & 10.40 & 31.95 & 7.43 \\
\hline
\end{tabular}

and Ni composition was found when an additional layer of pDA was incorporated. Parodontax immobilization yielded surfaces with a chemical signature similar to pDA coating alone. However, the presence of PEG and the other compounds of this formulation may play a role on such results.

CHX immobilization, using both one and two-step pDA-based approaches, was also corroborated by ATR-FTIR analysis (Fig. S4). Results showed that bare SS before and after dopamine polymerization (pDA) exhibited very similar spectra. According to Daud et al. [37], polydopamine presence should be evidenced by the appearance of $\mathrm{N}-\mathrm{H}$ stretching vibrations in the secondary amine at $3360 \mathrm{~cm}^{-1}$ and primary amine at $1606 \mathrm{~cm}^{-1}$. The absence of peaks in our samples may be attributed to the fact that we used a 10 -fold lower concentration of dopamine, which may have prevented the detection of these characteristic peaks. Further functionalization of surfaces with CHX using both one and two-step approaches resulted in the appearance of a peak between 2850 and $3000 \mathrm{~cm}^{-1}$, which corresponds to alkane $\mathrm{C}-\mathrm{H}$ stretching vibrations derived from the long hydrocarbon chain of CHX, as previously reported [37]. Although less evident, physical adsorption of $\mathrm{CHX}$ without polydopamine as an intermediate also exhibited this characteristic peak.

\subsubsection{Surface morphology}

Surface morphology was evaluated by SEM analysis (Fig. 2). Results showed that unmodified SS exhibited the typical microstructure of the laminated surfaces of SS, characterized by the presence of randomly aligned grooves and ridges $[38,39]$. After pDA coating, it was possible to observe the presence of self-polymerized pDA particles resulting from the bulk solution, which has been previously reported [25]. Further functionalization with CHX resulted in different morphologies, depending on the approach used. One-step immobilization of CHX yielded surfaces with a more homogeneous appearance with agglomerates more evenly distributed along the surfaces, as previously reported $[29,40]$. When CHX was immobilized using the two-step approach, no significant differences were found as compared to pDA coating alone. The addition of another layer of pDA generated surfaces with more and bigger pDA agglomerates across the entire surface. SS functionalization with PTX resulted in a cloudlike surface morphology, mainly observed by AFM (Fig. S3), which may be attributed to the presence of PEG in its formulation [41].

\subsubsection{Surface roughness and wettability and $\mathrm{CHX}$ release profile}

Using the AFM analysis, it was also possible to measure the average roughness of surfaces (Fig. 3A). Results showed that pDA coating did not introduce significant changes on surface roughness as well as further functionalization with CHX following a two-step approach or with a subsequent addition of another layer of pDA. One-step approach, on the other hand, caused a reduction on the surface roughness while PTX immobilization generated surfaces with significant higher values of roughness.

Surface wettability before and after each modification step was investigated by measuring the static water contact angles (Fig. 3B). Bare SS exhibited a hydrophobic surface, as evidenced by the water contact angle of approximately $94.1^{\circ} \pm 5.1^{\circ}$. Further functionalization with pDA rendered SS with hydrophilic properties as evidenced by the decrease on the water contact angle to $46.8^{\circ} \pm 6.0^{\circ}$, which is a well-established observation on materials functionalized with pDA [28]. Whatever the followed approach, further functionalization with CHX did not interfere with this hydrophilic character provided by sole pDA coating. These results are not in accordance to Daud et al. [37], reporting that CHX immobilization using a two-step pDA-based approach increased the hydrophobicity of the modified surfaces. These found differences may be attributed to the pre-treatment of SS surfaces performed by these authors, as opposed to the samples used in this study. SS roughness seemed to be more determinant on the contact angle measured than the
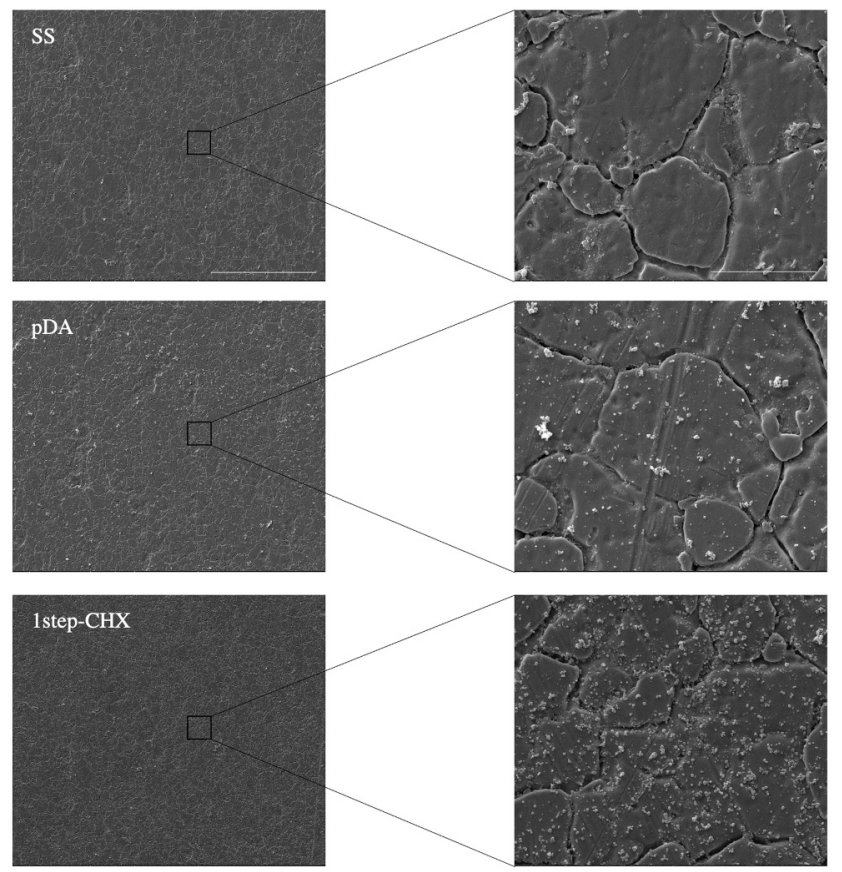
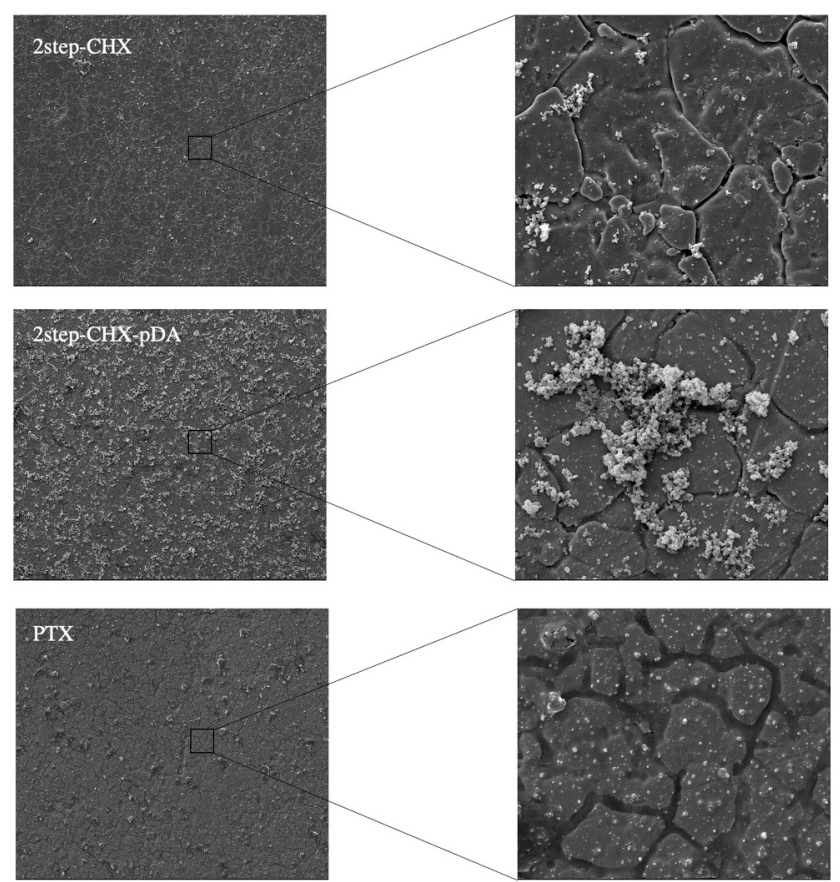

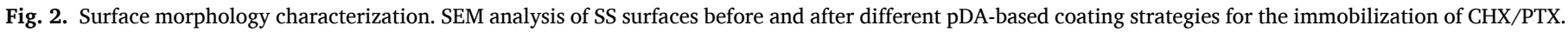
The scale bars in the left and right column indicate 100 and $10 \mu \mathrm{m}$, respectively 


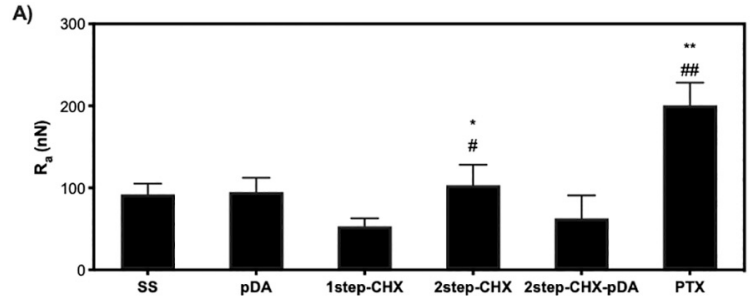

B)

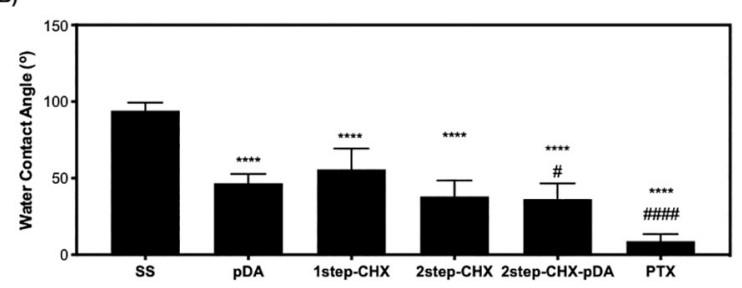

C)

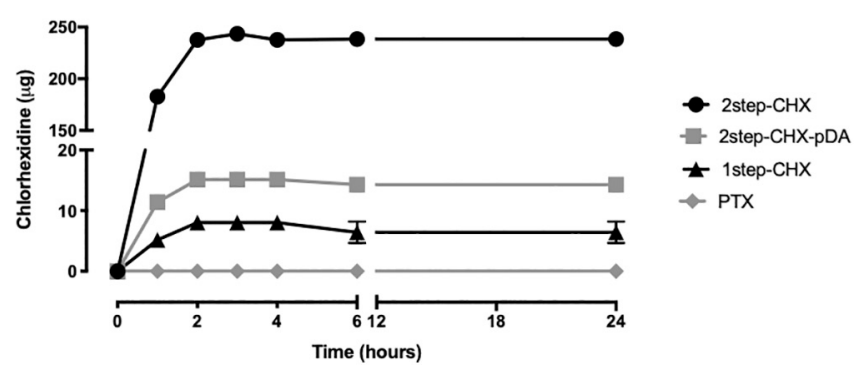

Fig. 3. Surface characterization. Average roughness (A), contact angles (B) and CHX cumulative release (C) from SS surfaces before and after different pDAbased coating strategies for the immobilization of CHX/PTX. Significant differences were found for $(* * * *) p<0.0001$, compared to SS and for $\left({ }^{\# \# \# \#) \mathrm{p}<}\right.$ 0.0001 and $\left({ }^{\#}\right) p<0.05$, compared to pDA.

immobilized CHX. Immobilization of PTX, on the other hand, greatly improved the hydrophilicity of SS surfaces, which may be attributed to the presence of PEG in this formulation and the previously demonstrated cloudlike arrangement [42].

The release profile of CHX from the different coating strategies is presented in Fig. 3C. Results showed that for all antimicrobial-releasing coating strategies, $\mathrm{CHX}$ was released in a burst-release fashion way, with most of the release occurring in the first $3 \mathrm{~h}$. The quantity of released CHX, however, varied with the immobilization strategy. Higher amounts were found for the two-step approach, while no CHX release was detected for the immobilization of PTX. This higher amount of released CHX may be attributed to some of the aforementioned physical adsorption. As intended, the amount of released CHX could be decreased (15-fold) by applying an outward layer of pDA or by using one-step immobilization strategy. These results corroborate the qualitative release assay previously showed in Table 1 and Fig. S2. It has been demonstrated that the amount of immobilized compounds depends on the performed pDA-based approach [40]. Therefore, the amount of released CHX may be a consequence of a higher efficiency of immobilization using the two-step approach.

Since immobilization of CHX, using a two-step approach followed by an additional layer of pDA (2step-CHX-pDA) and the one-step approach (1step-CHX), exhibited a similar CHX release profile, the latter approach was chosen for further investigation, as it comprises a simpler and less time-consuming coating strategy.

\subsection{Antimicrobial performance of coatings}

To evaluate the antimicrobial performance of the coating strategies against $S$. aureus and $S$. epidermidis, surfaces were first exposed to bacterial suspensions for $24 \mathrm{~h}$. The number of adhered cells and the cells found around the SS coupons, in the bulk phase, were enumerated (Fig. 4A and B).

Results showed that both species were able to adhere to unmodified SS surfaces and a higher number of adhered cells was found for $S$. aureus, as compared to $S$. epidermidis (Fig. 4A). The presence of pDA had no interference on the adhesion of $S$. aureus while enhancing the attachment of $S$. epidermidis, as noticed by the higher number of adhered cells. CHX immobilization using both one-step and two-step approaches was able to completely prevent the attachment of $S$. epidermidis. When it comes to $S$. aureus, both strategies impaired the surfaces of SS with similar antimicrobial features, causing a significant reduction on the number of adhered cells to an average number below the detection limit. The observed variability for these conditions is attributed to the range of $\log$ between 0 (when no colonies are found) and 2 (when only one colony is detected). Immobilization with PTX only caused reductions of approximately 1.4 and $1.6 \log$ on the adhesion of S. epidermidis and $S$. aureus, respectively. Since the goal of this study was to prevent bacterial adhesion to the modified surfaces themselves, while also eradicating the cells in their surroundings, the number of cells in the bulk phase was also determined (Fig. 4B). Results showed that SS before or after pDA coating did not interfere with both species growth. Bacterial growth was, however, compromised in the presence of all modified surfaces. Immobilization of CHX using both one and two-step approaches caused reductions on the number of cells to an average number below the detection limit. In a similar way to what was found for the adhered cells, surfaces functionalized with PTX exhibited less antimicrobial activity as compared to other strategies, with reductions of approximately 4.5 and $2.5 \mathrm{log}$, respectively, on the number of free $S$. epidermidis and $S$. aureus.

Antimicrobial performance was also evaluated for a longer period of time, 10 days, to strengthen the application of these coatings in orthopedics (Fig. 4C and D). Fig. 4C shows that both species adhered to control surfaces (SS and pDA), reaching similar values to the ones achieved after $24 \mathrm{~h}$. Both one and two-step approaches completely prevented the attachment of $S$. aureus during these 10 days of challenge. Regarding $S$. epidermidis, it was possible to observe some colonies adhered to the modified surfaces, after one-step approach. It should be stressed out, however, that more than $3 \log$ reduction was still achieved. Surfaces further functionalized with PTX exhibited similar number of adhered cells of both species to the ones found on control surfaces (SS and $\mathrm{pDA}$ ), an evidence that antimicrobial features provided by this approach were lost after being challenged for a longer period of time. Regarding the number of cells in the bulk phase (Fig. 4D), results showed that the presence of SS and pDA did not affect the growth of both species. Bacterial growth of both species was not compromised by the presence of surfaces further functionalized with PTX and no growth was observed when cells are near the surfaces modified with CHX, using both one and two-step approaches.

\subsection{Evaluation of resistance development by planktonic and adhered cells to $\mathrm{CHX}$}

The ability of CHX to induce bacterial resistance was first determined when free in solution against planktonic cultures of $S$. epidermidis and S. aureus (Table 3).

Results showed a 2-fold increase in MIC and MBC of both species, after 10 days of continuous exposure to a sub-inhibitory concentration of CHX, an evidence that planktonic cultures of $S$. epidermidis and $S$. aureus have become less susceptible to CHX.

A similar assay was performed to evaluate the potential development of resistance towards immobilized CHX. For that, adhered cells, in 


\section{Surface}

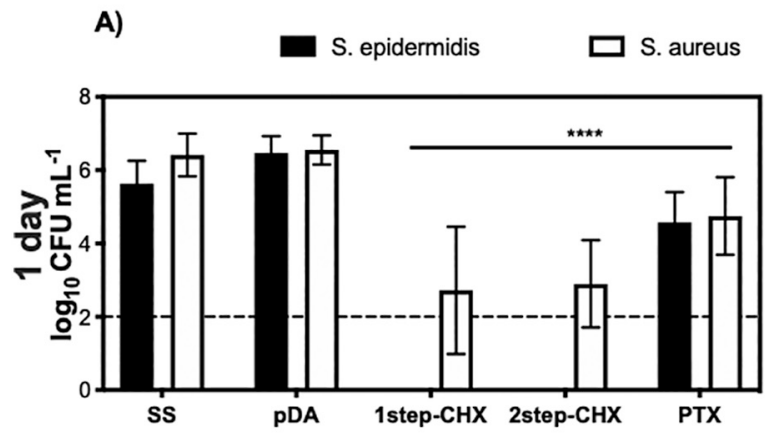

C)

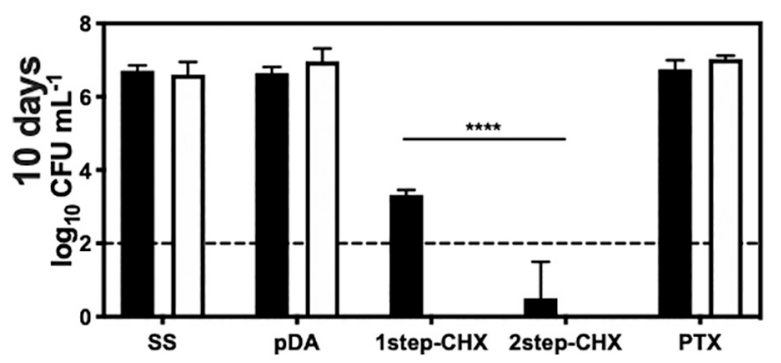

\section{Bulk phase}

B)

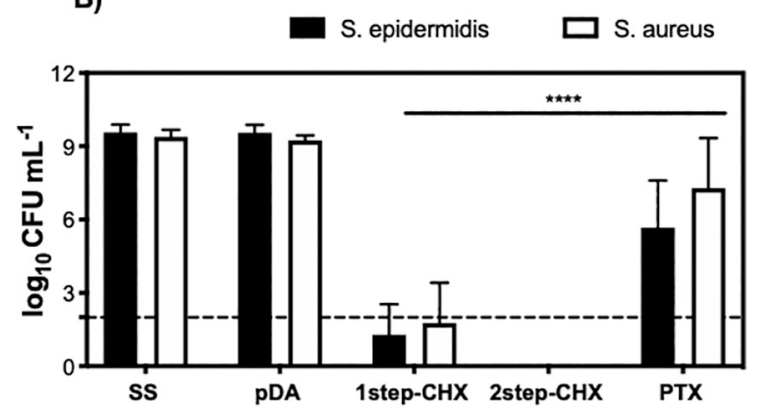

D)

S. epidermidis $\square$ S. aureus

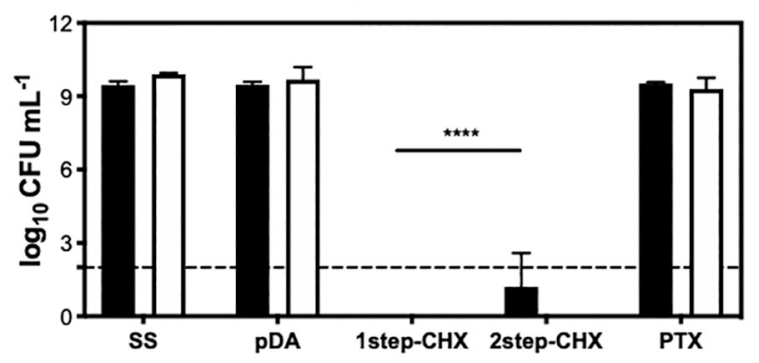

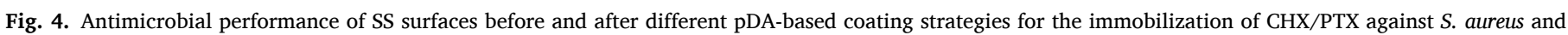

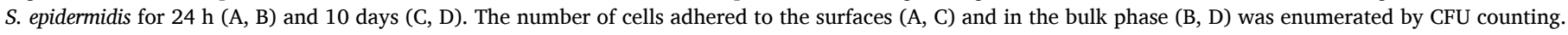

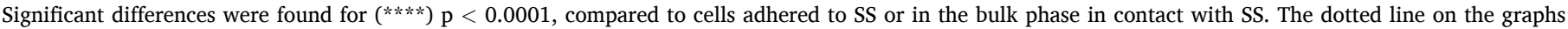
correspond to the detection limit of CFU counting $\left(\log 2 \mathrm{CFU} \mathrm{mL} \mathrm{m}^{-1}\right.$ ).

Table 3

Antimicrobial susceptibility of planktonic cultures of $S$. epidermidis and $S$. aureus towards CHX: MIC and MBC on day 0 and after 10 passages in a sub-inhibitory concentration of CHX. MIC and MBC are expressed in $\mu \mathrm{g} \mathrm{mL}^{-1}$.

\begin{tabular}{|c|c|c|c|c|}
\hline & \multicolumn{2}{|c|}{ S. epidermidis } & \multicolumn{2}{|c|}{ S. aureus } \\
\hline & MIC & MBC & MIC & MBC \\
\hline Day 0 & 0.4 & 0.4 & 0.4 & 0.8 \\
\hline Day 10 & 0.8 & $0.4-0.8$ & 0.8 & $0.8-1.6$ \\
\hline
\end{tabular}

contact with unmodified and modified SS surfaces for 10 days, were collected and used to determine the MIC and MBC of CHX.

Results in Table 4 showed that cells recovered from modified surfaces displayed the same susceptibility patterns of cells in contact with control surfaces (SS and pDA), suggesting no development of resistance. When it comes to the 2step-CHX approach for both species and 1stepCHX for $S$. aureus, MIC and MCB could not be determined since no cells could be recovered from these surfaces (Fig. 4).

Table 4

MIC and MBC of CHX against adhered S. epidermidis and S. aureus recovered from SS surfaces before and after different pDA-based coating strategies for the immobilization of CHX/PTX, after 10 days of exposure. MIC and MBC are expressed in $\mu \mathrm{g} \mathrm{mL}{ }^{-1}$. ND denotes not determined.

\begin{tabular}{llllll}
\hline \multirow{2}{*}{ Surface } & \multicolumn{2}{l}{ S. epidermidis } & & & \multicolumn{2}{l}{ S. aureus } \\
\cline { 2 - 3 } \cline { 5 - 6 } & MIC & MBC & & MIC & MBC \\
\hline SS & 0.4 & 0.4 & 0.4 & 0.8 \\
pDA & 0.4 & 0.4 & & 0.4 & 0.8 \\
1step-CHX & 0.4 & 0.4 & ND & ND \\
2step-CHX & ND & ND & & ND & ND \\
PTX & 0.4 & 0.4 & & 0.4 & 0.8 \\
\hline
\end{tabular}

\subsection{Cytotoxicity of coatings}

To strengthen the applicability of the coating strategies as biomaterials, their totoxicity on fibroblast cells was determined using the MTS assay (Fig. 5).

Results showed that unmodified SS surfaces, before and after pDA coating, did not exhibit any cytotoxic effect, providing good conditions for fibroblasts growth. Further functionalization of surfaces with PTX or CHX using one-step approach did not compromise cells metabolic activity, an evidence of no toxicity. The immobilization of CHX using the two-step approach, on the contrary, caused a reduction of cell viability superior to $30 \%$. Therefore, it should be considered harmful and incompatible as biomaterial [32]. Cytotoxicity exhibited by this approach may be attributed to the higher release of CHX, since it has been previously shown that CHX toxicity towards mammalian cells was dose-dependent [43].

\section{Discussion}

With the goal to fulfil the requirements of an anti-infective strategy for orthopedic implants, it was intended to design a coating strategy able to prevent bacterial attachment to the modified surfaces themselves, but also to the surrounding cells in the bulk phase. This should be accomplished with the combination of antimicrobial releasing and contactkilling features. CHX was chosen to impart surfaces with such antimicrobial features because of its antimicrobial mode of action. As a positively charged molecule, it has been postulated that CHX's mode of action is mainly based on electrostatic interaction with bacterial membranes with subsequent disruption of membrane's structural stability [23]. Since CHX target is not intracellular, its immobilization should not compromise its antimicrobial action. Dopamine chemistry was used to tailor the immobilization of $\mathrm{CHX}$ and subsequent release from SS 


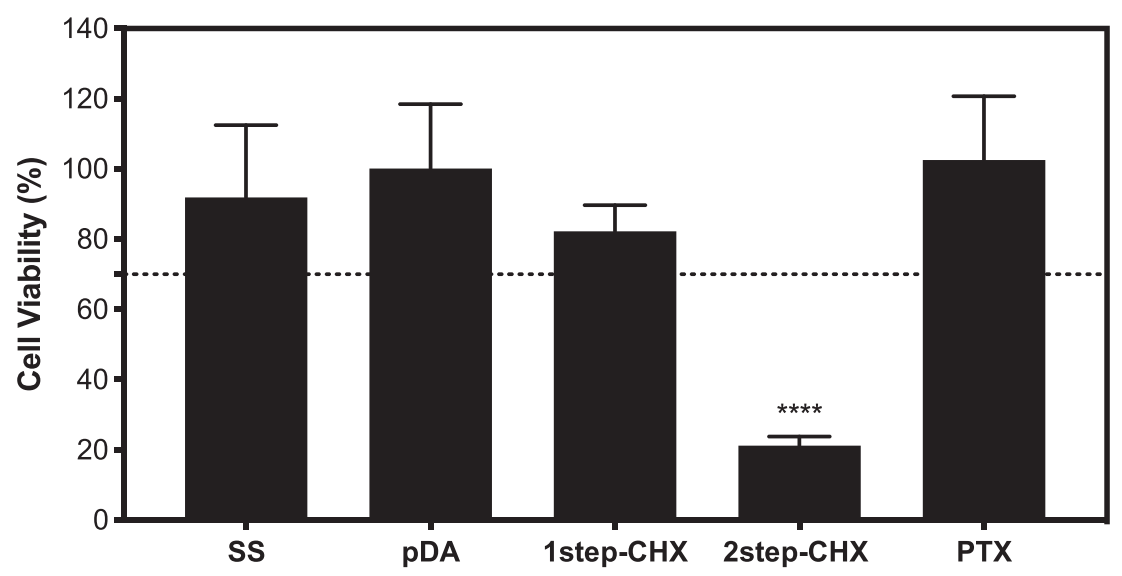

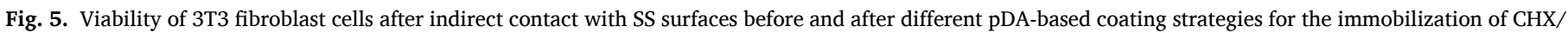

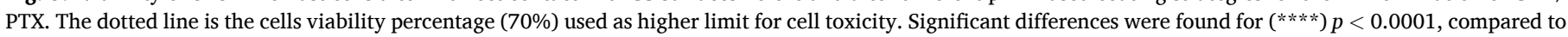
viability cells after indirect contact with SS.

surfaces, resulting in coating strategies with different surface properties, antimicrobial and biocompatible features.

A previous work has highlighted the potential of the conventional two-step pDA-based approach for the immobilization of CHX on metallic surfaces, providing them with antimicrobial features and no cytotoxicity [37]. The present study demonstrated, however, that using smaller concentrations of both dopamine and CHX, an antimicrobial and releasing approach could still be generated. In terms of antimicrobial features, this strategy was able to eradicate both bacterial species in suspension, which suggests its ability to prevent bacterial contamination from the implant surface to the surrounding tissues, if applied in a clinical context [15]. Such powerful antimicrobial performance may be attributed to the higher amount of released $\mathrm{CHX}$, based on the damage of the bacterial membrane of both $S$. aureus and $S$. epidermidis with subsequent leakage of cytoplasmic content. However, this amount of CHX was also toxic to mammalian cells, a drawback often associated to antimicrobial releasing coating strategies [44]. The next step was, then, to modulate CHX release so that it retains its antimicrobial features without compromising the growth of mammalian cells, which was first performed by adding a layer of pDA to create an additional diffusion barrier [41].

A constriction associated to the two-step pDA-based immobilization strategy (involving the formation of a pDA layer before compound immobilization on top of this intermediate layer) is that the amount of the immobilized agent is limited to the amount of reactive quinone groups that can react, which, in turn, is limited to the surface area of the outer surface [40]. To overcome this limitation, a one-step procedure has been reported and it is characterized by dopamine selfpolymerization in the presence of the compound. Such strategy results in the incorporation of active agents throughout the full thickness of the pDA layer rather than only at its outer surface [45]. CHX immobilization using this approach corroborated a previous work showing that this strategy results in a more homogeneous coating as compared to the conventional two-step approach [29]. In addition, improved surface features were obtained, namely the decrease on its roughness, a desired characteristic for further clinical application. In terms of antimicrobial performance, similar features were provided, as compared to the conventional two-step approach, with the additional advantage of not compromising the growth of fibroblast cells. To strengthen the applicability of this coating strategy on orthopedic devices, other line cells should be further tested, namely osteoblast-like cells. However, previous findings [46] demonstrating that SS functionalized with CHX was still able to induce the formation of apatite layer, and to support osteoblast cells attachment, differentiation and osteogenic maturation, are a good indication for the coating proposed in this study.

Since it is well established that the first $6 \mathrm{~h}$ after implant surgery (the so-called "decisive period") are critical to prevent infection and assure its long-term success, the coating strategies proposed in this study were tailored to release most of the CHX within the firs $6 \mathrm{~h}$ [47]. Furthermore, a rapid CHX initial release has previously proved to be effective in preventing $S$. aureus colonization of both the implants and surrounding tissue in a murine subcutaneous implant infection model [15]. Nevertheless, taking into account the long periods of time orthopedic devices are usually inserted in the human body, coating strategies designed for these devices should not quickly deplete the antimicrobial compound. For this reason, as well as to explain the observed antimicrobial performance for up to 10 days, modified surfaces were immersed on PBS for $24 \mathrm{~h}$, under agitation. After this period, an antimicrobial and a leaching assay was then performed for both species and results confirmed that CHX was still immobilized after the first $24 \mathrm{~h}$, as evidenced by the antimicrobial features (Fig. S5A) and presence of an inhibition zone (Fig. S5B). Inhibition zones were smaller than the ones found on Fig. S2, in which surfaces were not immersed on PBS. These outcomes reinforce that although most of CHX release has occurred in the first $3 \mathrm{~h}$, which can be attributed to some physical adsorption, the continuous antimicrobial performance observed for a longer period of time may be attributed to a more stable CHX immobilization. We believe that a combined effect should take place: some bacterial killing was accomplished in the bulk phase by fast released CHX, impairing bacterial attachment to the surfaces, but also some killing by contact with CHX still immobilized should occur by electrostatic interaction.

In this study, a contact-killing approach was used as a control of no CHX release. The absence of CHX release may be attributed to the presence of PEG in its composition, which enabled CHX immobilization on the surfaces [48]. The antimicrobial performance of this coating strategy observed after $24 \mathrm{~h}$ of bacterial challenge was lost when considering a longer period of time. Such results highlight the importance of achieving complete eradication of cells surrounding the surfaces, since the surviving cells will be able to proliferate and adhere to the implant surfaces. Moreover, after a contact of $24 \mathrm{~h}$, a significant number of cells were still found attached to the modified surfaces which may be a sign of a problem often associated to contact-killing surfaces: the accumulation of dead bacteria on the surfaces [49]. So, even if the coating strategy is able to kill the first adherent cells, it may allow the attachment of other bacteria and its consequent proliferation, resulting in more bacterial accumulation on the surface, while simultaneously reducing the antimicrobial activity over time, which was observed in this study.

Despite the CHX powerful antimicrobial features, its widespread use has led to some concerns regarding the emergence of bacterial resistance [50]. More recently, it has become the subject of great interest since it was reported that adaption in vitro of clinical isolates of Klebsiella 
pneumoniae to CHX can result in stable resistance towards it, as well as cross-resistance towards the last line antibiotic colistin [51]. The Staphylococci strains used in this study also exhibited an in vitro adaption to sub-inhibitory concentrations of $\mathrm{CHX}$ in solution, which strengthen these concerns. CHX immobilization can offer an advantage, as it has been showed that immobilized antimicrobial compounds show less propensity for developing bacterial resistance [52]. However, for antimicrobial releasing strategies, such as the ones presented in this study, a scenery in which the agent reaches sub-inhibitory concentrations after its release can present a problem. In general, for both one-step and two-step pDA-based immobilization of $\mathrm{CHX}$, a rapid initial release was obtained, being sufficient to effectively eradicate the cells surrounding the surface and subsequently prevent their attachment. In such approaches, resistance development should not be an issue. For the strategies where adhered cells were found after 10 days of continuous challenge (PTX for both species and 1step-CHX for S. epidermidis), cells were recovered and their susceptibility to $\mathrm{CHX}$ was determined. Results showed that these cells exhibited a similar susceptibility pattern as the cells recovered from the control surfaces with no CHX (SS and pDA), thus suggesting no development of resistance in these conditions. These results corroborate the theory that compounds immobilization decreases their propensity to induce bacterial resistance [52,53]. It should also be mentioned that the probable very low amount of CHX still remaining on these surfaces can also contribute for this absence of resistance development.

\section{Conclusions}

In conclusion, dopamine chemistry was successfully applied to tailor the CHX immobilization and subsequent release from SS surfaces, resulting in coating strategies with different surface properties, antimicrobial and biocompatible features. Immobilization of CHX using a onestep pDA-based strategy proved to be the most promising approach to be further applied in the fight of infections associated to orthopedic implants. This simpler approach provided the surfaces with the ability to prevent bacterial colonization of the surface, while eradicating bacteria surrounding the surface in suspension for 10 days long. The few bacteria that managed to adhere onto these surfaces did not show evidence of resistance towards CHX. Moreover, the released amount of CHX did not compromise the growth of mammalian cells.

\section{CRediT authorship contribution statement}

All authors listed have made a substantial, direct and intellectual contribution to the work, and approved it for publication.

\section{Declaration of competing interest}

The authors declare that they have no known competing financial interests or personal relationships that could have appeared to influence the work reported in this paper.

\section{Acknowledgements}

This study was supported by the Portuguese Foundation for Science and Tecnhnology (FCT) under the scope of the strategic funding of UID/ BIO/04469/2020 unit and BioTecNorte operation (NORTE-01-0145FEDER-000004) funded by the European Regional Development Fund under the scope of Norte2020-Programa Operacional Regional do Norte. The authors also acknowledge the support, through the Programa Operacional Competitividade e Internacionalização (COMPETE2020) and by national funds, through the FCT, of the POLY-PrevEnTT project (PTDC/BTMSAL/29841/2017-POCI-01-0145-FEDER-029841) and the PhD Grant of Tânia Grainha (SFRH/BD/136544/2018).

\section{Appendix A. Supplementary data}

Supplementary data to this article can be found online at https://doi. org/10.1016/j.msec.2020.111742.

\section{References}

[1] P.H. Long, Medical devices in orthopedic applications, Toxicol. Pathol. 36 (2008) 85-91.

[2] S. Kurtz, K. Ong, E. Lau, F. Mowat, M. Halpern, Projections of primary and revision hip and knee arthroplasty in the United States from 2005 to 2030, J. Bone Jt. Surg. - Ser. A 89 (2007) 780-785.

[3] M. Ribeiro, F.J. Monteiro, M.P. Ferraz, Infection of orthopedic implants with emphasis on bacterial adhesion process and techniques used in studying bacterialmaterial interactions, Biomatter 2 (2012) 176-194.

[4] A.J. Tande, R. Patel, Prosthetic joint infection, Clin. Microbiol. Rev. 27 (2014) $302-345$.

[5] A.G. Gristina, Biomaterial-centered infection: microbial adhesion versus tissue integration, Science (80-.) 237 (1987) 1588-1595.

[6] H.J. Busscher, H.C. van der Mei, G. Subbiahdoss, P.C. Jutte, J.J.A.M. van den Dungen, S.A.J. Zaat, M.J. Schultz, D.W. Grainger, Biomaterial-associated infection: locating the finish line in the race for the surface, Sci. Transl. Med. 4 (2012) $153 r v 10$.

[7] H. Koo, R.N. Allan, R.P. Howlin, P. Stoodley, L. Hall-Stoodley, Targeting microbial biofilms: current and prospective therapeutic strategies, Nat. Rev. Microbiol. 4 (2017) 740-755.

[8] M.S. Parikh, S. Antony, A comprehensive review of the diagnosis and management of prosthetic joint infections in the absence of positive cultures, J. Infect. Public Health 9 (2016) 545-556.

[9] A.K. Muszanska, E.T.J. Rochford, A. Gruszka, A.A. Bastian, H.J. Busscher, W. Norde, H.C. Van Der Mei, A. Herrmann, Antiadhesive polymer brush coating functionalized with antimicrobial and RGD peptides to reduce biofilm formation and enhance tissue integration, Biomacromolecules 15 (2014) 2019-2026.

[10] M.A. Azab, M.J. Allen, J.B. Daniels, Evaluation of a silver-impregnated coating to inhibit colonization of orthopaedic implants by biofilm forming methicillinresistant Staphylococcus pseudintermedius, Vet. Comp. Orthop. Traumatol. 29 (2016) 347-350.

[11] E.P. Lautenschlager, G.W. Marshall, K.E. Marks, J. Schwartz, C.L. Nelson, Mechanical strength of acrylic bone cements impregnated with antibiotics, J. Biomed. Mater. Res. 10 (1976) 837-845.

[12] H. Forster, J.S. Marotta, K. Heseltine, R. Milner, S. Jani, Bactericidal activity of antimicrobial coated polyurethane sleeves for external fixation pins, J. Orthop. Res. 22 (2004) 671-677.

[13] M. Lucke, G. Schmidmaier, S. Sadoni, B. Wildemann, R. Schiller, N.P. Haas, M. Raschke, Gentamicin coating of metallic implants reduces implant-related osteomyelitis in rats, Bone 32 (2003) 521-531.

[14] E. Gullberg, S. Cao, O.G. Berg, C. Ilbäck, L. Sandegren, D. Hughes, D.I. Andersson, Selection of resistant bacteria at very low antibiotic concentrations, PLoS Pathog. 7 (2011), e1002158.

[15] M. Riool, A.J. Dirks, V. Jaspers, L. de Boer, T.J.A. Loontjens, C.M. van der Loos, S. Florquin, I. Apachitei, L.N.D. Rijk, H.A. Keul, S.A.J. Zaat, A chlorhexidinereleasing epoxy-based coating on titanium implants prevents Staphylococcus aureus experimental biomaterial-associated infection, Eur. Cells Mater. 33 (2017) $143-157$.

[16] R.G. Wilkins, M. Unverdorben, Wound cleaning and wound healing: a concise review, Adv. Skin Wound Care 26 (2013) 160-163.

[17] L.G.M. Ribeiro, L.N. Hashizume, M. Maltz, The effect of different formulations of chlorhexidine in reducing levels of mutans streptococci in the oral cavity: a systematic review of the literature, J. Dent. 35 (2007) 359-370.

[18] A. Obermeier, J. Schneider, S. Wehner, F.D. Matl, M. Schieker, R. Von EisenhartRothe, A. Stemberger, R. Burgkart, Novel high efficient coatings for anti-microbial surgical sutures using chlorhexidine in fatty acid slow-release carrier systems, PLoS One 9 (2014), e101426.

[19] D.G. Maki, S.M. Stolz, S. Wheeler, L.A. Mermel, Prevention of central venous catheter-related bloodstream infection by use of an antiseptic-impregnated catheter: a randomized, controlled trial, Ann. Intern. Med. 127 (1997) 257-266.

[20] B. Basrani, J.M. Santos, L. Tjäderhane, H. Grad, O. Gorduysus, J. Huang, H, P. Lawrence, S. Friedman, Substantive antimicrobial activity in chlorhexidinetreated human root dentin, Oral Surg. Oral Med. Oral Pathol. Oral Radiol. Endod. 94 (2002) 240-245.

[21] M.P.T. Otten, H.J. Busscher, H.C. Van Der Mei, F. Abbas, C.G. Van Hoogmoed, Retention of antimicrobial activity in plaque and saliva following mouthrinse use in vivo, Caries Res. 44 (2010) 459-464.

[22] H.Y. Cheung, M.M.K. Wong, S.H. Cheung, L.Y. Liang, Y.W. Lam, S.K. Chiu, Differential actions of chlorhexidine on the cell wall of bacillus subtilis and Escherichia coli, PLos One 7 (2012), e36659.

[23] T. Kuyyakanond, L.B. Quesnel, The mechanism of action of chlorhexidine, FEMS Microbiol. Lett. 100 (1992) 211-215.

[24] I. Francolini, C. Vuotto, A. Piozzi, G. Donelli, Antifouling and antimicrobial biomaterials: an overview, APMIS 125 (2017) 392-417.

[25] I.S. Kwon, C.J. Bettinger, Polydopamine nanostructures as biomaterials for medical applications, J. Mater. Chem. B 6 (2018) 6895-6903.

[26] H. Lee, S.M. Dellatore, W.M. Miller, P.B. Messersmith, Mussel-inspired surface chemistry for multifunctional coatings, Science (80-.) 318 (2007) 426-430. 
[27] D. Alves, A.T. Vaz, T. Grainha, C.F. Rodrigues, M.O. Pereira, Design of an antifungal surface embedding liposomal amphotericin B through a mussel adhesive-inspired coating strategy, Front. Chem. 7 (2019) 1-9.

[28] D. Alves, A. Magalhães, D. Grzywacz, D. Neubauer, W. Kamysz, M.O. Pereira, Coimmobilization of Palm and DNase I for the development of an effective antiinfective coating for catheter surfaces, Acta Biomater. 44 (2016) 313-322.

[29] D. Alves, M.O. Pereira, Bio-inspired coating strategies for the immobilization of polymyxins to generate contact-killing surfaces, Macromol. Biosci. 16 (2016) 1450-1460.

[30] CLSI, CaLS I, Methods for Dilution Antimicrobial Susceptibility Tests for Bacteria That Grow Aerobically, 2003.

[31] R.A. Cooper, L. Jenkins, A.F.M. Henriques, R.S. Duggan, N.F. Burton, Absence of bacterial resistance to medical-grade manuka honey Eur, J. Clin. Microbiol. Infect. Dis. 29 (2010) 1237-1241.

[32] International Organization for Standardization, Biological Evaluation of Medical Devices, 2009.

[33] H. Lee, J. Rho, P.B. Messersmith, Facile conjugation of biomolecules onto surfaces via mussel adhesive protein inspired coatings, Adv. Mater. 21 (2009) 431-434.

[34] T. Kanzian, T.A. Nigst, A. Maier, S. Pichl, H. Mayr, Nucleophilic reactivities of primary and secondary amines in acetonitrile, Eur. J. Org. Chem. 6370-85 (2009).

[35] X. Jie, Y. Shang, Z.N. Chen, X. Zhang, W. Zhuang, W. Su, Differentiation between enamines and tautomerizable imines in the oxidation reaction with TEMPO, Nat. Commun. 9 (2018) 1-10.

[36] P. Zhou, Y. Deng, B. Lyu, R. Zhang, H. Zhang, H. Ma, Y. Lyu, S. Wei, Rapidlydeposited polydopamine coating via high temperature and vigorous stirring: formation, characterization and biofunctional evaluation, PLoS One 9 (2014), e113087.

[37] N. Mohd Daud, I.F. Saeful Bahri, N.A.N. Nik Malek, H. Hermawan, S. Saidin, Immobilization of antibacterial chlorhexidine on stainless steel using crosslinking polydopamine film: towards infection resistant medical devices, Colloids Surf. B: Biointerfaces 145 (2016) 130-139.

[38] S. Wu, S. Altenried, A. Zogg, F. Zuber, K. Maniura-Weber, Q. Ren, Role of the surface nanoscale roughness of stainless steel on bacterial adhesion and microcolony formation, ACS Omega 3 (2018) 6456-6464.

[39] M. Haïdopoulos, S. Turgeon, G. Laroche, D. Mantovani, Chemical and morphological characterization of ultra-thin fluorocarbon plasma-polymer deposition on 316 stainless steel substrates: a first step toward the improvement of the long-term safety of coated-stents, Plasma Process. Polym. 2 (2005) 424-440.

[40] A.W.G. Nijhuis, J.J.J.P. van den Beucken, O.C. Boerman, J.A. Jansen, S.C. G. Leeuwenburgh, 1-Step versus 2-step immobilization of alkaline phosphatase and bone morphogenetic protein-2 onto implant surfaces using polydopamine, Tissue Eng. Part C Methods 19 (2013) 610-619.
[41] T.S. Sileika, Kim H. Do, P. Maniak, P.B. Messersmith, Antibacterial performance of polydopamine-modified polymer surfaces containing passive and active components, ACS Appl. Mater. Interfaces 3 (2011) 4602-4610.

[42] Z. Xiong, L. Zhao, F. Wang, J. Zhu, H. Qin, R. Wu, W. Zhang, H. Zou, Synthesis of branched PEG brushes hybrid hydrophilic magnetic nanoparticles for the selective enrichment of N-linked glycopeptides, Chem. Commun. 48 (2012) 8138-8140.

[43] T. Arabaci, H. Türkez, C.F. Çanakçi, M. Özgöz, Assessment of cytogenetic and cytotoxic effects of chlorhexidine digluconate on cultured human lymphocytes, Acta Odontol. Scand. 71 (2013) 1255-1260.

[44] J.J.T.M. Swartjes, P.K. Sharma, T.G. Kooten, H.C. Mei, M. Mahmoudi, H. J. Busscher, E.T.J. Rochford, Current developments in antimicrobial surface coatings for biomedical applications, Curr. Med. Chem. 22 (2014) 2116-2129.

[45] S.M. Kang, N.S. Hwang, J. Yeom, S.Y. Park, P.B. Messersmith, I.S. Choi, R. Langer, D.G. Anderson, H. Lee, One-step multipurpose surface functionalization by adhesive catecholamine, Adv. Funct. Mater. 22 (2012) 2949-2955.

[46] N. Mohd Daud, R. Hussein Al-Ashwal, M.R. Abdul Kadir, S. Saidin, Polydopamineassisted chlorhexidine immobilization on medical grade stainless steel 316L: apatite formation and in vitro osteoblastic evaluation, Ann. Anat. 220 (2018) 29-37.

[47] K.A. Poelstra, N.A. Barekzi, A.M. Rediske, A.G. Felts, J.B. Slunt, D.W. Grainger, Prophylactic treatment of gram-positive and gram-negative abdominal implant infections using locally delivered polyclonal antibodies, J. Biomed. Mater. Res. 60 (2002) 206-215.

[48] H.J. Chae, E.Y. Kim, M.J. In, Improved immobilization yields by addition of protecting agents in glutaraldehyde-induced immobilization of protease, J. Biosci. Bioeng. 89 (2000) 377-379.

[49] B.R. Coad, H.J. Griesser, A.Y. Peleg, A. Traven, Anti-infective surface coatings: design and therapeutic promise against device-associated infections, PLoS Pathog. 12 (2016), e1005598.

[50] G. Kampf, Acquired resistance to chlorhexidine - is it time to establish an 'antiseptic stewardship' initiative? J. Hosp. Infect. 94 (2016) 213-227.

[51] M.E. Wand, L.J. Bock, L.C. Bonney, J.M. Sutton, Mechanisms of increased resistance to chlorhexidine and cross-resistance to colistin following exposure of Klebsiella pneumoniae clinical isolates to chlorhexidine, Antimicrob. Agents Chemother. 61 (2017), e01162-16.

[52] D.F. Alves, A.P. Magalhães, D. Neubauer, M. Bauer, W. Kamysz, M.O. Pereira, Unveiling the fate of adhering bacteria to antimicrobial surfaces: expression of resistance-associated genes and macrophage-mediated phagocytosis, Acta Biomater. 78 (2018) 189-197.

[53] J. Bruenke, I. Roschke, S. Agarwal, T. Riemann, A. Greiner, Quantitative comparison of the antimicrobial efficiency of leaching versus nonleaching polymer materials, Macromol. Biosci. 16 (2016) 647-654. 